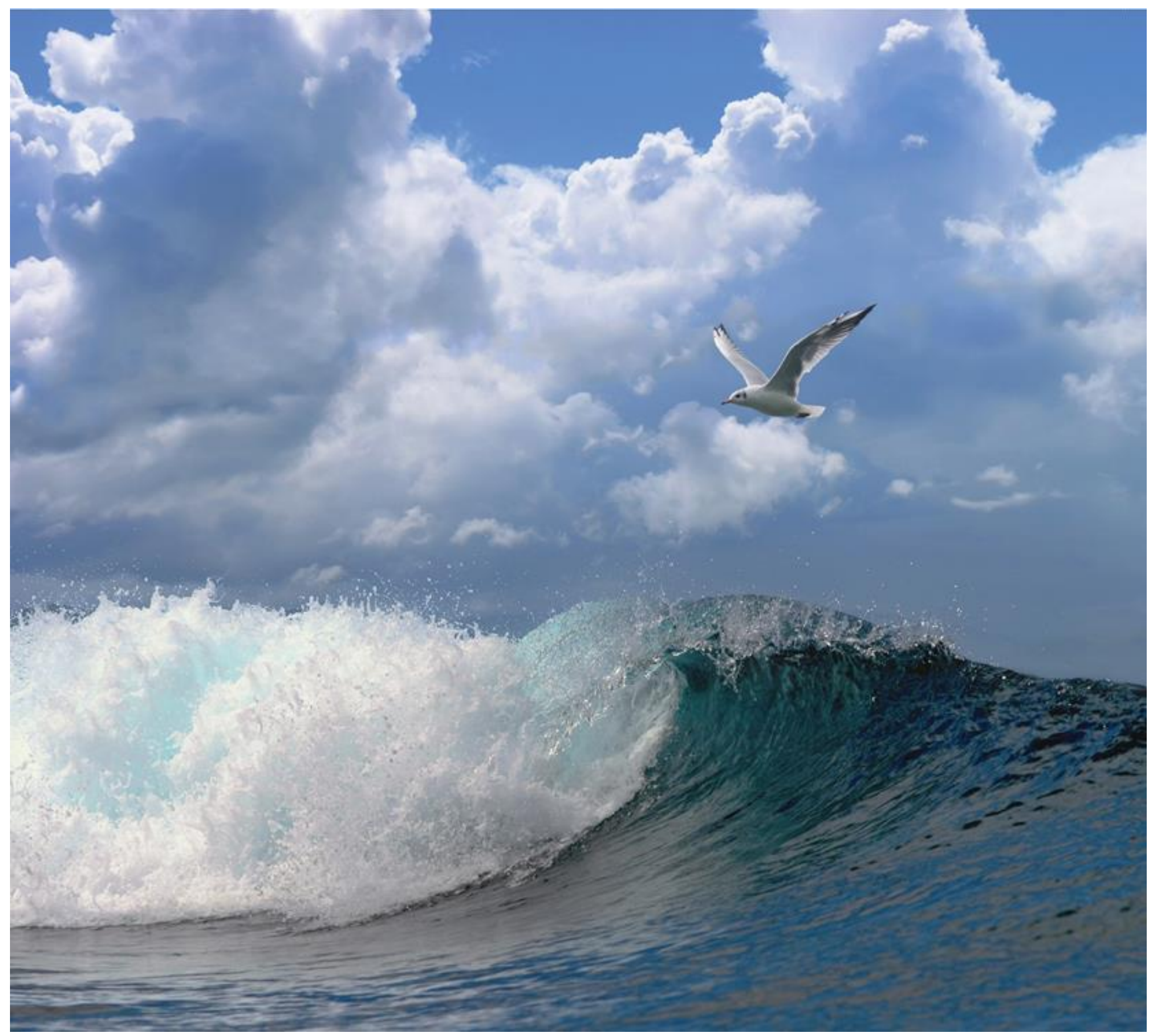

The consequences of seabird habitat loss from offshore wind turnines: a research plan for five selected species 


\section{The consequences of seabird habitat loss from offshore wind turbines: a research plan for five selected species}

Author(s): Tobias van Kooten, Floor Soudijn \& Mardik Leopold

Publication date: 25 september 2018 
Tobias van Kooten, Floor Soudijn \& Mardik Leopold. The consequences of seabird habitat loss from offshore wind turbines: a research plan for five selected species. Wageningen, Wageningen Marine Research, Wageningen Marine Research report C069/18. 30 pp.

Client: $\quad$ Rijkswaterstaat Water, Verkeer en Leefomgeving

Attn.: Dr. I. van Splunder

P.O. Box 2232

$3500 \mathrm{GE}$, Utrecht

Dit rapport is gratis te downloaden van https://doi.org/10.18174/460458

Wageningen Marine Research verstrekt geen gedrukte exemplaren van rapporten.

Wageningen Marine Research Wageningen UR is ISO 9001:2008 gecertificeerd.

(c) 2018 Wageningen Marine Research Wageningen UR

Wageningen Marine Research, onderdeel van Stichting Wageningen Research KvK nr. 09098104,

IMARES BTW nr. NL 8113.83.696.B16.

Code BIC/SWIFT address: RABONL2U

IBAN code: NL 73 RABO 0373599285
De Directie van Wageningen Marine Research is niet aansprakelijk voor gevolgschade, noch voor schade welke voortvloeit uit toepassingen van de resultaten van werkzaamheden of andere gegevens verkregen van Wageningen Marine Research opdrachtgever vrijwaart Wageningen Marine Research van aanspraken van derden in verband met deze toepassing.

Dit rapport is vervaardigd op verzoek van de opdrachtgever hierboven aangegeven en is zijn eigendom. Niets uit dit rapport mag weergegeven en/of gepubliceerd worden, gefotokopieerd of op enige andere manier gebruikt worden zonder schriftelijke toestemming van de opdrachtgever. 


\section{Contents}

1 Introduction $\quad 4$

$\begin{array}{lll}1.1 & \text { Clarification } & 4\end{array}$

$\begin{array}{lll}1.2 & \text { Background } & 4\end{array}$

$\begin{array}{lll}1.3 & \text { Problem definition } & 4\end{array}$

1.4 Aim of the work presented in this work plan 4

2 Analysis $\quad 6$

$\begin{array}{lll}2.1 & \text { General outline and structure } & 6\end{array}$

$\begin{array}{lll}2.1 .1 & \text { How to measure population effects } & 7\end{array}$

2.2 Analysis components $\quad 8$

2.2.1 Habitat models $\quad 8$

2.2.2 Degree of avoidance model 12

2.2.3 Energy budget model 13

2.2.4 Population dynamical model 15

$3 \quad$ Work plan $r 2$

$\begin{array}{lll}3.1 & \text { Team } & 22\end{array}$

$\begin{array}{lll}3.1 .1 & \text { People } & 22\end{array}$

3.2 Work organization $\quad 23$

3.2.1 Client involvement $\quad 23$

$\begin{array}{lll}3.2 .2 & \text { Project team communication } & 23\end{array}$

$\begin{array}{lll}3.2 .3 & \text { Timing } & 23\end{array}$

$\begin{array}{lll}3.3 & \text { Accountability } & 24\end{array}$

3.3.1 Wozep data lab $\quad 24$

$\begin{array}{lll}\text { 3.3.2 } & \text { Reproducibility of analyses \& figures } & 24\end{array}$

$4 \quad$ Quality Assurance $r 25$

$\begin{array}{lr}\text { References } & 26\end{array}$

$\begin{array}{lr}\text { Justification } & 29\end{array}$ 


\section{Introduction}

\subsection{Clarification}

This document is a work plan for future research. All text in this work plan is related to that future research. Hence, none of the text presented here is a reflection on the current assignment which is to develop the work plan. This is different from the standard practice, which is that reports from commissioned projects reflect the activities within those projects. This is most relevant for the introductory text. For example, the following paragraph '1.2 Background' describes the background of the work plan, not the background of the assignment to write the work plan.

\subsection{Background}

The Dutch government intends to increase the number of offshore wind turbines in its territorial waters in the next years. These turbines potentially have negative effects on the seabirds using these waters. Some seabirds suffer mortality from collisions with turbine blades, while others avoid the areas and consequently may suffer habitat loss. While the Dutch government aims for a transition to renewable energy, it also has a responsibility for the preservation of seabirds using its territorial waters.

\subsection{Problem definition}

In order to develop the Dutch offshore wind agenda, as outlined in the 'Energie-akkoord voor duurzame groei' (2013), in an ecologically sound way, the KEC ('Kader Ecologie en Cumulatie') was compiled. This document gives an overview of species and populations where potential problems occur between fauna and the planned OWF ('Offshore Wind Farm') development, and highlights potential mitigating measures to prevent these problems. The research described in this plan follows directly from the KEC: it aims to do a further study of the top five seabird species deemed most at risk from the Dutch offshore wind farms through displacement and habitat loss. The project will not consider the effect of wind farms on seasonal, long-distance bird migration patterns.

\subsection{Aim of the work presented in this work plan}

The aim of the work described in this plan is to develop and apply an assessment method for OWF induced habitat loss. The effect of habitat loss will be assessed for five seabird species deemed most likely to suffer detrimental population effects from OWF plans in Dutch waters. The assessment will consider the red-throated diver, northern gannet, razorbill, common guillemot and the sandwich tern. All five have shown a strong tendency to avoid OWFs (Dierschke et al. 2016). Important aspects of the assessment method are:

- It translates effects that are measurable in the field (e.g. the degree of avoidance of individuals of species $X$ to turbines) to indicators that are relevant for policy (e.g. the \%decline of a population over $X$ years as a consequence of Dutch OWF)

- It takes a precautionary approach in dealing with uncertainty, and is able to quantify the effect of taking this approach (e.g. by showing the difference between the precautionary approach and the 'best estimate').

- It is able to differentiate between different spatial configurations/locations of OWF, and can be used for scenario studies.

- It takes into account the OWF plans of other North Sea countries. 
- It is reproducible and built on the basis of good scientific practice

- It takes all relevant and available information on the ecology of the species concerned into account 


\section{Analysis}

\subsection{General outline and structure}

The goal of this analysis is to quantify the effects, as a result of habitat loss, of OWF development in Dutch waters on the population development of common guillemots, razorbills, northern gannets, redthroated divers and sandwich terns using the Dutch continental shelf. This analysis consists of a number of elements of OWF-induced habitat loss which together allow us to assess the (potential) influence of habitat loss for individual birds on their population development. Four sub-questions can be formulated that are the focus of different parts of the analysis, but which fit together logically to address the overall goal (Figure 1). The sub-questions are:

1. What is the importance of the areas occupied by OWFs and what alternatives are available?

2. What is the degree of OWF avoidance of each of the species and does habituation occur?

3. What is the (direct) cost of this habitat loss (in terms of time and/or energy)? And, how do the results from the above questions combine to change the population vital rates (e.g. reproduction, survival), given different OWF scenarios?

4. What are the population consequences of these changes in vital rates?

The approach to each of the elements of this analysis will be based on a common framework for the five species studied here, but will be adapted to reflect both the specific ecology and life history of each species and the availability of species-specific knowledge and data.

Question 1 will be answered using state-of-the-art habitat models (section 2.2.1), which couple bird observational count data to biotic and abiotic independent variables. From these, the most appropriate model will be selected based on statistical considerations (e.g. the Akaike Information Criterion) and relevance to the research question. These models are spatially explicit and can be used to calculate the effects of OWF scenarios, including variations in the location of OWFs.

Question 2 will be answered using a degree of avoidance model (section 2.2.2). The model will determine the degree of avoidance for each of the bird species and different OWF scenarios based on observational data.

Question 3 will be answered using an energy-budget model (section 2.2.3). The habitat models will be used, together with the OWF scenarios to be developed and the degree of avoidance, to calculate the energetic costs of bird redistribution due to a change in the availability and configuration of the foraging area. Finally, we determine the 'cost' of the scenarios in terms of reduced vital rates. This requires a translation of energetic costs into changes in reproductive rate and survival and will be done using a behavioural simulation model.

Question 4 will be answered using a population dynamical model (section 2.2.4). These models also allow for estimates of sensitivity of the results to parameter uncertainty and environmental stochasticity, and such analysis will be conducted. 


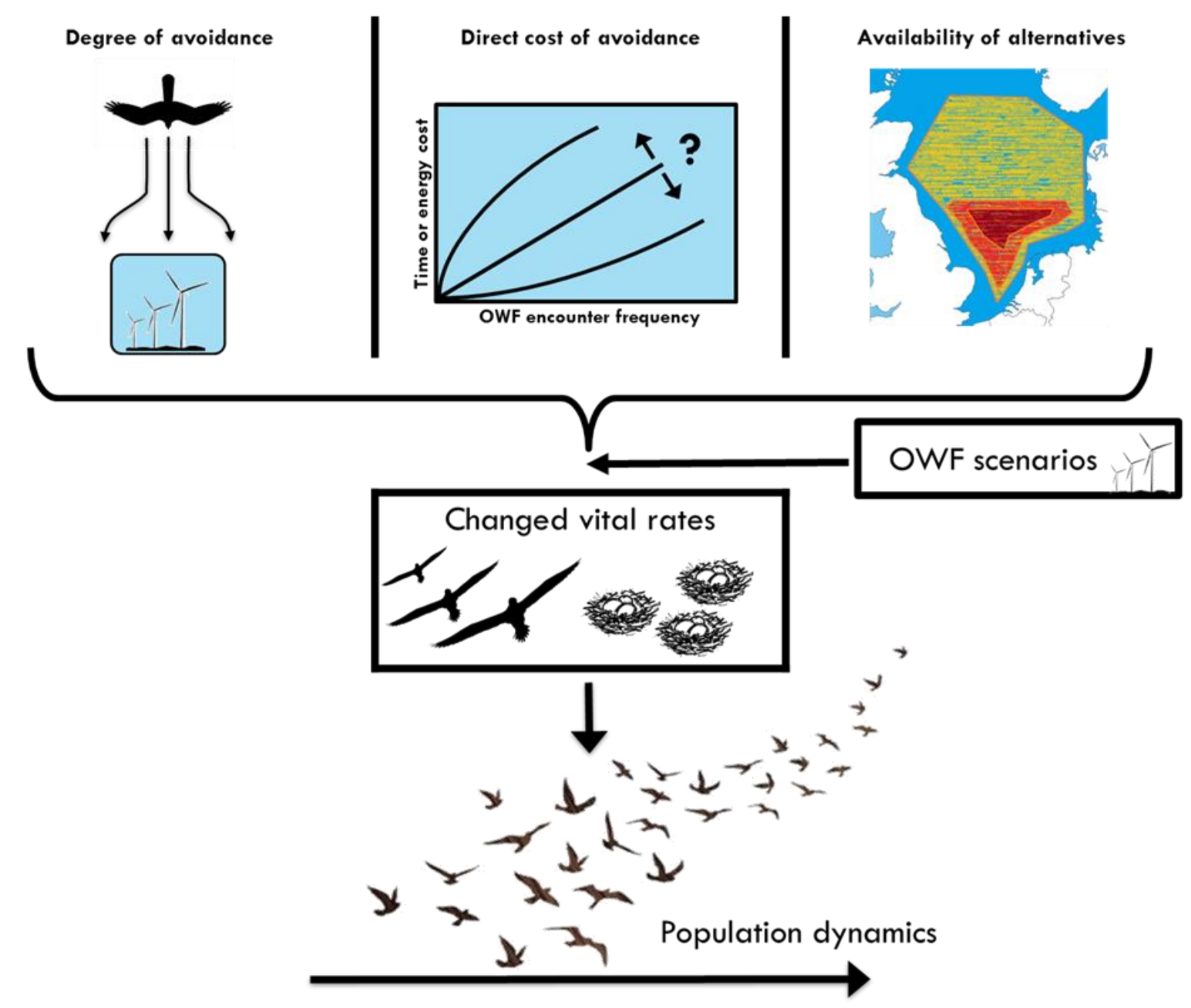

Figure 1 Schematic representation of proposed analysis. Studies on the degree of avoidance, the cost of avoidance and the availability of alternative foraging habitat are aimed at calculating expected changes in vital rates (growth, reproduction, survival) given the OWF development scenario under study. These changed rates are then used to study the effects of each scenario on the population dynamics.

\subsubsection{How to measure population effects}

A multitude of indicators has been used to quantify the impact of offshore wind on seabird populations (Cook \& Robinson, 2016). Generally, these indicators fall into one of two categories: 1. those derived from an analytical sensitivity analysis of model parameters (e.g. how do changes in the parameter values affect factors such as the population growth rate); and, 2 . those that are derived from (stochastic) model time series (e.g. the relative abundance of the population at a certain point in the time series, comparing a population with and without a disturbance). Each has its strong and weak points. The analytically derived indicators are better suited for systematic model analysis and understanding the sensitivity to specific model assumptions, whereas the time series based indicators can be used to contrast control/impact scenarios in the presence of stochasticity. We will use both approaches. Cook \& Robinson (2016) show that generally the more simple, straightforward indicators perform best.

The population model analysis that we plan (see 2.2.4), allows for population projections (i.e. calculation of time series) of the relevant units (specific bird colonies and/or all of the birds that occupy the North Sea) for each of the species. A comparison of the projection with and without the OWFs will give an estimate of the change in population size due to the OWFs. In addition, we will calculate population growth rates for the five seabirds with and without the OWFs. The magnitude of these (if positive) is an indication of how the recovery potential (or resilience) of the populations is 
affected by the OWFs. A switch from positive to negative implies a change from population growth or stability to a decline.

Using the output of all the steps in the analysis we will calculate the effect of a range of different scenarios on the population level indicators (Table 1). We will focus on a 'realistic scenario' based on the best available knowledge, and a 'worst case scenario' based on more pessimistic assumptions within the bandwidth of the uncertainty of parameter values. The latter approach corresponds to an application of the precautionary approach.

Table 1 Indicators of population level effects and projection scenarios

\begin{tabular}{ll}
\hline Population level indicator & Interpretation \\
\hline Population growth rate & 1. Resilience of the population to disturbance \\
Stochastic population projections & 2. Does the population switch from growth to decline? \\
Extinction probability & Probability of an X\% decline over Y years \\
& $\begin{array}{l}\text { Probability of extinction of the population over a Y year } \\
\text { period }\end{array}$ \\
\hline Scenarios & Levels \\
\hline Dutch OWF & Without \\
\hline Habituation & With \\
UK OWF (particularly effect during & Without \\
breeding season) & With (varying time scale) \\
Without \\
OWF & Realistic scenario \\
Habitat loss mortality & Worst-case scenario \\
& To be determined (two scenarios) \\
Breeding success & Realistic scenario \\
Environmental stochasticity & Worst-case scenario \\
& $10 \%$ mortality (standard approach) \\
& Realistic scenario \\
& Worst-case scenario \\
& Realistic scenario \\
& Worst-case scenario \\
\hline
\end{tabular}

\subsection{Analysis components}

\subsubsection{Habitat models}

\subsubsection{Principle and approach}

Habitat models are spatial statistical models that are used to extrapolate local observational data (samples, counts), by relating these data to independent (environmental) variables. By relating the occurrence of a species to environmental variables, these models allow for the translation of spatial data of the environmental variables into continuous maps of expected abundances. This approach allows for an extrapolation of species abundances from sampled to un-sampled locations. The sum of these expected abundances for the whole area is an estimate of the number of individuals predicted to be present there. Bird count data are a typical example of data that give only a fragmented view of actual abundances. Habitat modelling maps are used to give estimates of bird abundances in certain areas (e.g. Berrevoets \& Arts 2002). The combination of data based on different count methods may allow for a distinction between species that cannot always be separated during the counts, such as razorbill and common guillemot (Johnston et al. 2015). Moreover, bird density maps have been taken as an indicator of habitat suitability, for example for the identification of Marine Important Bird Areas (MIBAs, Poot et al. 2010). MIBAs are then used as a starting point for the identification of areas that are suitable for MPAs (Lambert et al. 2017). 
Habitat models are used in this framework to estimate a. the number of a certain bird species in the total relevant area (North Sea, Dutch Continental Shelf, etc.), based on observational data and b: the relative importance of smaller areas, which are potentially designated for location of OWF.

The construction of a habitat model generally starts by constructing a hypothesis regarding which independent variables are important determinants of the distribution of the species under study. Examples of such variables are food availability, distance to breeding colonies and water depth. State-of-the-art Bayesian statistical techniques (R-INLA) will be used to infer relationships between the chosen variables and the number of birds on a spatial grid. The quality of a habitat model is generally measured as its capacity to describe the data with which it is fed, offset against the number of free parameters used for fitting. The Akaike Information Criterion summarizes this quality and is commonly used to choose a 'best model' among a number of variants.

\subsubsection{Data needs and availability}

These models require first and foremost observational data (time, location and sighting) of the species under study. Such data is generally collected using ships or airplanes as survey platforms (but see below). These observations are the dependent variable (the quantity to be predicted) of the habitat model. The independent variables are the other (a-)biotic factors prevailing at the time and location of each observation. Which independent variables are relevant depends on the species under study. In practice, only part of the relevant data will be available.

The quality of models obtained -and the possibility to conduct model selection- depend on both the quantity and the quality of available data. Data quality is determined not only by the quality of the observations or measurements, but also by the range of values in each variable covered in the data. Values spanning a larger range generally increase the quality and will lead to better models. Examples are: observations over a wide geographical range, observations spanning a wide range of prey availabilities, spread out throughout the year (or relevant season), etc.

A special category of observations is data from GPS trackers, which collect continuous location data. These data, when available, can also be used to inform habitat models.

Habitat models have been previously designed for all the bird species that we study in the current project (Table 2), but not always for the same season and area that is applicable here. We will include a range of abiotic and biotic variables in the habitat models. The presence of different bird species may have an effect on the abundance of a certain bird. For the sake of simplicity we have decided not to include this factor in the analysis.

Habitat models range from simple, based on only a few abiotic variables (e.g. Poot et al. 2010, see Table 2) to very complex, with dynamical modelling of the variables (e.g. Skov et al. 2016). Depending on the bird species different variables may be considered important. For example, for the Northern gannet, it was found that including hydrodynamics is important (Skov et al. 2008). Habitat mapping around breeding colonies of razorbill and common guillemot, on the other hand, was improved by including a measure for the densities of conspecifics (Wakefield et al. 2017). Habitat models for abundances around breeding colonies typically include the distance to the breeding colony and the maximum feeding range of the species (Table 2). For habitat models during the non-breeding season, the distance to land is more informative.

Table 2. Variables in existing (non-dynamical) habitat modelling studies of the Northern gannet, common guillemot, razorbill, red-throated diver and sandwich tern

\begin{tabular}{lll}
\hline Study subject & Source & variables \\
\hline Northern gannet & Skov et al. 2008 & Distance to Bass Rock Colony \\
Breeding colony, Bass Rock & Distance to land \\
& Bathymetry of sea floor \\
& Slope of sea floor \\
& Eastern aspect of sea floor \\
& Northern aspect of sea floor \\
& North Sea water mass \\
& Scottish coastal water mass \\
\hline
\end{tabular}




\begin{tabular}{|c|c|c|}
\hline Study subject & Source & $\begin{array}{l}\text { variables } \\
\text { Forth River plume front }\end{array}$ \\
\hline $\begin{array}{l}\text { Northern gannet, common } \\
\text { guillemot, razorbill } \\
\text { Dogger Bank in the North Sea }\end{array}$ & Johnston et al. 2015 & $\begin{array}{l}\text { Sea surface temperature } \\
\text { Distance to coast } \\
\text { Distance to colony } \\
\text { Depth } \\
\text { Season } \\
\text { Sandeel }\end{array}$ \\
\hline $\begin{array}{l}\text { Divers, sandwich tern, } \\
\text { Northern gannet } \\
\text { Dutch North Sea }\end{array}$ & Poot et al. 2010 & $\begin{array}{l}\text { Depth } \\
\text { Distance from coast }\end{array}$ \\
\hline $\begin{array}{l}\text { Red-throated diver } \\
\text { German bight }\end{array}$ & Zydelis (presentation) & $\begin{array}{l}\text { Depth } \\
\text { Distance to wind farms } \\
\text { Current } U \text { velocity } \\
\text { Current } \mathrm{V} \text { velocity } \\
\text { Salinity } \\
\text { Water temperature }\end{array}$ \\
\hline $\begin{array}{l}\text { Red-throated diver } \\
\text { Scottish waters } \\
\text { breeding colonies }\end{array}$ & Black et al. 2015 & $\begin{array}{l}\text { Depth } \\
\text { Seabed slope } \\
\text { Seabed aspect } \\
\text { Maximum wave base } \\
\text { Maximum tidal bed stress } \\
\text { Sea surface temperature } \\
\text { Salinity } \\
\text { Stratification } \\
\text { Probability of fronts } \\
\text { Seabed substratum } \\
\text { Coastal physiography }\end{array}$ \\
\hline $\begin{array}{l}\text { Common guillemot, razorbill } \\
\text { Scottish waters } \\
\text { breeding colonies }\end{array}$ & Wakefield et al. 2017 & $\begin{array}{l}\text { Density conspecifics } \\
\text { Distance colony } \\
\text { Distance to coast } \\
\text { Sediment } \\
\text { Seabed slope } \\
\text { Sea surface temperature } \\
\text { Thermal front gradient density. }\end{array}$ \\
\hline $\begin{array}{l}\text { Common guillemot, razorbill } \\
\text { Dutch North Sea }\end{array}$ & Berrevoets \& Arts 2002 & $\begin{array}{l}\text { Depth } \\
\text { Distance from coast }\end{array}$ \\
\hline $\begin{array}{l}\text { Common guillemot } \\
\text { Californian Current }\end{array}$ & Nur et al. 2011 & $\begin{array}{l}\text { Latitude } \\
\text { Minimum depth } \\
\text { Mean depth } \\
\text { Contour index } \\
\text { Distance to } 200-\mathrm{m} \text { isobath } \\
\text { Distance to } 1000-\mathrm{m} \text { isobath } \\
\text { Distance to } 3000-\mathrm{m} \text { isobath } \\
\text { Distance to nearest land } \\
\text { Day of year } \\
\text { SOI } 0-2 \text { months before }\end{array}$ \\
\hline $\begin{array}{l}\text { Sandwich tern } \\
\text { North Norfolk Coast SPA } \\
\text { breeding colonies }\end{array}$ & Thaxter et al. 2011 & $\begin{array}{l}\text { Depth } \\
\text { Aspect Eastness } \\
\text { Aspect Northness } \\
\text { Slope } \\
\text { Chemistry Salinity } \\
\text { Seabed Temperature } \\
\text { Temperature Stratification } \\
\text { Summer Front Frequency } \\
\text { Wave Shear Bed Stress } \\
\text { Current Shear Bed Stress } \\
\text { Sediment Type } \\
\text { Distance to Shore } \\
\text { Distance to Colony }\end{array}$ \\
\hline
\end{tabular}


For modelling at-sea seabird distribution, data are needed on seabird counts at sea (density estimates) that are geo-referenced. Such data are readily available from two sources:

1. the ESAS (European Seabirds At Sea) database (mostly ship-based counts of seabirds), kept at JNCC, Aberdeen, covering the entire North Sea and,

2. For the Dutch section of the North Sea only, the MWTL database (available via Noordzeeloket, Rijkswaterstaat).

A recent data-extract from both databases has been used for modelling seabird distribution patterns in the Southern North Sea (Leopold et al. 2014), but counting seabirds at sea is ongoing, particularly on the Dutch Continental Shelf (MWTL). We aim to use the most recent version of the data, which includes as much of the recent data we can obtain. In order to do so, it may be needed to convince people and organizations which have additional data which is not yet uploaded to ESAS, to do so. Here, RWS may be able to provide some leverage.

All (major) seabird colonies have been mapped and census data from around the North Sea have been brought together in Mitchell et al. (2004). It should be possible to zoom in on more recent data for key-colonies by accessing the Seabird Colony Register in the UK (through Ian Mitchell), data from Helgoland (for gannet and guillemot; through Stefan Garthe) and the sandwich tern network (in The Netherlands; several colleagues). Only for red-throated diver colony data are not available (as this species does not breed in colonies, but rather dispersed over huge areas). The most recent general population estimates can be obtained from BirdLife International (factsheets, online) and Wetlands International (2010).

GPS tagging studies yield the most fine-grained data on spatial distribution of seabirds. However, tagging studies are usually conducted during the breeding season, and as such the data is limited to that period. A number of published studies exist for different colonies of several of species of interest here:

- Garthe et al (2017): A GPS logger-based study of the effects of German OWF on the Helgoland breeding colony of Northern Gannets

- Cleasby et al (2015): GPS logger-based habitat model of Northern Gannets breeding in the Bass Rock colony.

- Wakefield et al (2013): GPS logger-based study into foraging of a number of UK Northern gannet colonies.

- Wakefield et al (2017): GPS logger-based habitat models of four seabirds including guillemots and razorbills.

- $\quad$ Fijn et al (2017): The first (and so far only) GPS logger study revealing the foraging distribution of sandwich terns in a breeding colony in the south of the Netherlands.

For 3 of these 4 species, it is likely that we can use existing, published habitat models for the breeding period. For sandwich terns, the data is available, but there is no published habitat model available yet. Red-throated divers do not breed in colonies, so the GPS tagging approach generally does not work very well. For sandwich terns, a further study is planned in the near future for the Texel breeding colony, the results of which are highly relevant for this work.

\section{Data availability - explanatory variables}

Potential explanatory variables can be divided into (bio)chemical/physical data and biological data. The first category can often be inferred from satellite data, and for the area of interest most of this data is available for (free) download from the EU marine environment monitoring service (http://marine.copernicus.eu). The data that can be obtained from this source includes temperature, salinity, mixed layer depth, wind, water transparency, chlorophyll a and nutrient concentrations. All these variables are available in sufficiently high spatial and temporal resolution. Well-established spatiotemporally resolved primary production estimates are available from Dr Michael Behrenfeld's group at Oregon State University, based on MODIS satellite data 
(www.science.oregonstate.edu/ocean.productivity/index.php). Zooplankton is a group for which there is notoriously little data. For a few species, spatiotemporal inferences from continuous plankton recorder data are available from EMODNET.

Standardized bathymetry for the entire area is available for free download from the British Oceanographic Data Centre and seafloor angle can be inferred from bathymetry. Seabed type (Eunis classification) can be obtained from the EMODNET data portal (http://www.emodnetseabedhabitats.eu/map). Distance to shore (or distance to colonies) are straightforward to generate from available land/water maps and colony locations.

Temporal data on prey fish abundance is not available, because annual sampling intensity from fish surveys is insufficient to generate spatial maps. However, spatial information averaged over many years is available from Heessen, Daan and Ellis (2015).

Data on fishing intensity may also be important for several of the species studied. Recent maps of bottom fishing intensity (various gear types) throughout the North Sea were produced within the BENTHIS EU project and this data is available for use (http://www.benthis.eu). Information of equal quality on pelagic fisheries is not available, but pelagic fisheries are far fewer vessels than bottom fisheries.

\subsubsection{Degree of avoidance model}

\subsubsection{Principle and approach}

Avoidance is not an all-or-nothing phenomenon. Most cases of seabirds avoiding wind farms are based on observations of lower abundances within the OWF compared to the surrounding area. It is generally thought that the degree of avoidance depends (among other factors) on the location and technical specifications of the OWF, in particular on the size of and distance between turbines. This type of model describes the degree of avoidance (zero to complete avoidance) of a species given the location, time of year, and certain technical specifications of OWFs, such as turbine size.

Furthermore, habituation may occur: individuals which initially avoid OWF may get used to their presence and overcome their initial response. Habituation would change avoidance from a permanent to a temporal effect, related to either a certain time after installation of each OWF, or to the development of OWF on the North Sea as a whole, so that birds will encounter it more frequently.

Through a parallel project (Leopold et al. in prep.), we expect to obtain a detailed degree of avoidance model for the common guillemot, including the effect of location and technical specifications of OWFs. Such understanding could lead to better quality estimates, especially in light of the ongoing trends to use ever-larger turbines offshore. For the other species, we will rely on the values given in Dierschke et al. (2016), and will consult with relevant experts on if and how we will implement habituation. When better estimates of avoidance become available in time, we will adopt those.

\subsubsection{Data requirements and availability}

To fit a model of this kind, observational data around existing OWFs is needed, preferentially both from before and after OWF placement. From such data, it is possible to estimate the degree of avoidance. For all species under study, a number derived using a degree of avoidance model can be found in the literature (Dierschke et al 2016). However, for guillemots a more detailed study is under way by Leopold et al. (in prep.).

Measurements of habituation would require long-term observations around existing OWFs. Unfortunately, such data is rare, because most OWF-specific monitoring and evaluation programmes stop at the latest five years after construction finishes. There are also not many scientific reports on habituation after OWF installation, but the ongoing data analysis on common guillemots suggests habituation continues in that species. We will consult with various experts on our species in relation to OWF avoidance to develop more understanding of the possibility for habituation. The analysis framework proposed here is fully capable of dealing with temporal effects. 


\subsubsection{Energy budget model}

\subsubsection{Principle and approach}

Energy budget models describe changes in the energetics of an individual given its state (weight, age, sex, energy reserves etc.) and the environment (food availability, temperature, etc.). Within the assessment framework developed here, these models are used to determine the energetic cost of lost habitat and translate this loss to changes in population level processes. These are generally so-called 'vital rates', the speed at which reproduction, mortality, immigration and emigration take place, given the population state (e.g. population size) and the environmental state (e.g. food availability).

The energetic cost is formulated in terms of either reduced energy intake (for example, when individuals relocate to lower quality feeding grounds) and/or increased energy expenditure (for example due to enhanced intra- or even interspecific competition for resources or from longer average flight times/distances to a breeding colony). Such effects on individual displaced birds can be further complicated when feeding is density-dependent, but very little information is available to quantify this aspect. The ultimate output of these models are the consequences of the additional costs for the individual bird: how much does offspring production and/or survival of individual birds change as a result of the reduced energy intake and/or increased energy expenditure related to the OWFs. Hence, these models deliver the translation from OWF placement scenario to the effect on the parameters used in the population dynamic models.

Energy budget models can vary from highly complex and detailed (for example, Dynamic Energy Budget Models; Kooijman 2009) to very simple (such as used, for example, in de Roos et al. 2007). The energy budget model we propose to use here is of the simpler kind. This is largely a pragmatic choice, because the more complex models are very time-consuming to develop and many of the necessary parameter values are unavailable for the species under study. Furthermore, these models are not an objective of the research, but an intermediate step to get from OWF placement to reductions in average vital rates. In light of the above, we have developed an alternative approach, which represents a pragmatic compromise based on available knowledge.

\subsubsection{A framework to estimate effect of displacement on (non-breeding) survival}

Of the five species which are the focus of this work, four spend much of their non-breeding time foraging in the North Sea. Only the sandwich tern consistently migrates to (West) Africa during the non-breeding season. The other four species are all potentially affected by the placement of OWFs in the Dutch North Sea during the entire non-breeding season. Methods to assess the effects of OWF on vital rates generally focus on the breeding season, when the birds are so-called central-place foragers (though there may be a non-breeding adult group which is not restricted to the colony location). This is a considerably different situation compared to the effects during the non-breeding period, when birds are not required to return to the breeding colony. Here, we suggest a method to assess effects during the non-breeding period.

1. Starting assumptions: Individuals are assumed to move around randomly, and feed whenever they encounter food. Movement is delayed by feeding and this is what causes local aggregations: individuals spend more time in high-food locations. Hence, we assume the observed seabird distribution is a result of food availability.

2. Individuals do not stay in areas where they have negative net energy, i.e. where metabolic cost outweighs intake. They do however move through such areas occasionally.

3. We will use the habitat model output (map) to define areas with (for example) the lowest $10 \%$ abundance. We qualify these as transit areas with zero feeding value and we call the mean abundance in these areas the 'ambient abundance'.

4. We assume that when an area becomes unavailable (i.e. becomes an OWF), the birds that were there are redistributed. We first take the number of birds estimated to be due to flying around and not feeding (ambient abundance times surface) and distribute this number of birds over all remaining locations equally. Then, the remaining 'relocation candidates' are added, in proportion to habitat 
quality, to all available areas which qualify as feeding grounds. We now have a modified habitat map where certain areas are closed and the birds that used those areas have been redistributed.

5. Because of the assumptions in 1 . we can take abundance as a measure of relative intake rate at that location. For simplicity, we assume that intake rate is proportional to food abundance, so that a change in food availability always has a (positive or negative) fitness effect.

6. We assume that individual energetics are given by: energetic state $(E)$ at time $t$ equals previous energetic state plus intake minus metabolic cost per unit time $t: E(t)=E(t-1)+I(t)-M$.

7. We assume that there is a threshold energetic state below which an individual dies instantly. We further assume that up to this threshold, fitness is unaffected. This may appear to be a 'hard' rule in the sense that either nothing is wrong, or the individual dies. The alternative would be to have a softer rule, where there is a range of energetic states where the individual has an increasing chance to die as the energetic state gets worse. However, the effect on the population level (the number of deaths as a result of adverse energetic state) would ultimately be the same. Because the simulation we propose to use is stochastic, the energetic state of an individual relative to the starvation threshold can be interpreted as an individual's short-term chance to die: when very close to the threshold, ending up in a bad patch only once will mean death, whereas an individual in a better state may have survived. In the end, either option requires us to specify a fraction surviving and a fraction dead.

8. There is no need to be specific about units of $E, I$ and $M$, since we are only interested in translating intake reduction into an effect on survival, not in any of the intermediate numbers. That means we can set the threshold, defined at point 7., equal to zero: if $E<0$, the individual dies.

9. We can now simulate individuals moving around on our habitat map during the season. We assume they move at random to available neighbouring cells (or stay where they are), and the chance to go to each specific cell is proportional to each location's bird abundance from the habitat model, which we have assumed in 1. to reflect food abundance. They do this each day (or whichever time step we find plausible). We simulate a group of individuals (e.g. 10000) moving around on the map. At the end of the season we estimate the proportion surviving as the fraction whose $E(t)$ has never become negative. The distance and frequency of movement should ideally be estimated from GPS tagging studies.

10. Given that we have survival probabilities from an independent source (as input for the population models), we can adjust the metabolic cost $M$ in our simulation in such a way that the mean annual survival from the simulation (using the standard Habitat model output map, without added OWFs) equals that value.

11. We can now use the modified habitat maps generated under 4 . and do the simulation with the $M$ as derived in 10 (corresponding to pre-OWF survival). The difference in the survival estimate which comes out of the simulation is then the estimated wind farm effect on mortality through the reduced energetic state. This will yield not only the new mean survival value but also the distribution around the mean, which we can use directly in our stochastic matrix models.

12. While the above focuses purely on lethal effects (mortality), the approach can be extended to include a threshold energetic state for successful breeding. Any individual with energetic state below this threshold is then assumed to be alive, but not able to breed the following season. If we have independent estimates of the non-breeding adult percentage, we can fit (in step 10) this energetic threshold such that the percentage of non-breeding adults corresponds to what we know it to be. Analogous to changes in mortality, step 11 will then give us an estimate of the energetics-driven effect of OWF on the chance an individual will participate in breeding.

The difference (with/without OWF) in mean energetic state of surviving individuals at the end of the non-breeding season is another output of the above model, which may be taken as an indicator of the reduced physical condition of adults starting the breeding season. A similar approach can be developed for the breeding season (below), in which the energetic state of surviving birds from the winter season can be used as an input parameter.

\subsubsection{A framework to estimate effect of displacement on breeding success}

The framework proposed here is actually much simpler, and does not require any simulation. This simplification is possible because energy needs to be delivered to the colony, so that each location has a fixed 'foraging cost' associated with it, whereas in the non-breeding case the cost is related to the current location of individuals. The start of the exercise is a habitat model around a colony. We 
assume that foraging parent birds attempt to optimize the rate at which energy is transported to the colony. This means that the output of the habitat model (a bird abundance) for each location is proportional to the rate at which energy is transported from that location to the colony. To compute the effect of wind farm-related habitat loss, we can compare the total value (all locations summed) in the situation with wind farms to that without. If we know the productivity (chicks per breeding pair per year) of the colony without wind farms, we can apply the wind farm related reduction to that number to obtain the wind farm induced effect on productivity.

One thing this framework cannot deal with is barrier effects, which results in longer travel distances between the colony and foraging locations as individuals need to fly around offshore wind farms. To study this we could implement a simulation analogous to that proposed for the nonbreeding season. An extra step in such a scenario would be to decompose the habitat model output into a cost component (proportional to flight distance to colony) and an intake component (energy acquired). A complicating factor here is that this requires an explicit treatment of the travel time, as (1) gains need to be offset not only against flight costs, but also against flight times and (2) we would need to consider the fact that individuals foraging far away will mean that a higher fraction of encountered birds will be 'in transit', which is also part of the data underlying the habitat model. Hence, this approach is substantially more complex (though possible), but does yield the possibility to include barrier effects.

Whether or not it is necessary to use the second approach depends on the OWF scenarios to be studied, and the extent to which potential barrier effects of existing wind farms on breeding colonies are known. The most likely case in which we need to apply the second option is to study the effects of Dutch OWF plans on breeding sandwich terns because they are known to breed relatively close to the area of the planned OWFs.

\subsubsection{Using required energy as an estimate of carrying capacity}

We will estimate the population-level food requirement of each of the five species by combining habitat model output (spatially explicit abundance estimates) with estimates of energy requirement. This gives a first indication of population-level food requirement, which can be compared to survey and/or fish stock assessment data for the same area (at least for some prey species), to see how they relate. This will give a first idea of whether or not food abundance may be an important regulating factor for population size of the particular species. This would likely be the case if feeding by birds over the year substantially reduces prey abundance.

\subsubsection{Data requirements and availability}

Detailed energy budget models require an understanding of the energetics of the species involved, including the division of energy to gonads and soma, dynamics of stored energy, (weight-specific) basic metabolic rate, costs of flight, foraging behaviour and food processing, reproductive investment etc. Such detailed knowledge is generally not available for the species of interest in this study. Even with such detailed information available, it is not immediately clear how energetic state mechanistically translates to survival and/or reproductive success. We hence do not plan to pursue full and quantitatively correct energy budget models.

The approach outlined in the section above represents a way which does not include the detailed energetic processes (e.g. storage, movement). Instead, the model uses the energetic state as a measure of individual fitness, which is reduced by metabolic costs and increased by feeding. This approach avoids the need for species-specific parameterization of the energetic model.

\subsubsection{Population dynamical model}

\subsubsection{Principle and approach}

A population dynamical model describes changes in numbers or biomass of a population and the population composition over time. Often, the population is structured into different life stages (size classes, juvenile/adult), or age classes and the dynamics of each of these is described. Processes that 
determine these changes are births, growth, aging, deaths, immigration and emigration. A population dynamical model can be used to estimate the population level effect of a disturbance on for example the population size, composition and/or population growth rate.

In the current assessment framework, population dynamical models serve two purposes. First, all models described above ultimately feed into the population dynamical models, which are then used to estimate the net population level effects of OWF scenarios. Second, analysing the effects of parameter changes on the dynamics of these models yields insight into the species' sensitivity to such changes. Such sensitivity analysis is an important tool to interpret the assessment results and guide further research. If we find, for example, that changes in a certain parameter are not important, we do not need to spend limited resources to determine more precise values. On the other hand, if we find extreme sensitivity to a certain parameter value, this could mean we have to rely on the precautionary approach principle, as we can never be 'sure enough' of the precise value.

\subsubsection{Choice of modelling framework}

A number of modelling frameworks are available to analyse population dynamics. Because the population level assessment supplies the final answer to the policy-relevant question, we need a modelling framework that can provide robust answers, based on well-established methods. One suggested model framework is that of individual-based simulation models (including agent-based models). This framework is appealing because it is intuitive: it allows for the specification and simulation of individual birds, the fate of which can be followed throughout a simulation. However, the framework also has drawbacks. There are 3 main arguments why we consider individual-based simulation techniques unsuitable for the current assignment.

1. Individual based simulation models can only be analysed using heuristics-based methods. This always leaves a degree of uncertainty about the completeness of the results. In particular, simulation-based analysis methods can never fully exclude the existence of alternative stable states in models. In contrast, a modelling framework with an analysis using mathematical techniques is certain to find all stable (and unstable) equilibrium states.

2. In constructing individual-based models it is necessary to translate conceptual ideas into computer code, which introduces additional complexity and assumptions. For example, when simulating birds feeding in a specific location, we must make an assumption about the order in which feeding takes place, simply because the computer can only carry out a single computation at a time. Such decisions can have strong effects on the outcome of the simulations. Merely listing and documenting all these implicit assumptions is difficult and time consuming, let alone analysing their effect on model outcomes.

3. These models require a lot of details to be specified, in particular details about the behaviour of individuals. This means that explicit choices have to be made about processes for which we have little idea how they really work. We can make assumptions to cover for uncertainties and test alternative assumptions, but we can never know whether or not using the correct mechanism would lead to a different model outcome. Using models formulated mathematically rather than as computer code allows us to use mathematical inference to study the effects of entire suites of mechanisms. This allows us to formulate much broader conclusions, such as 'any density-dependence in the relationship between $x$ and $y$ can never qualitatively change result $z$ '.

Seabirds display so-called 'pulsed reproduction': they only reproduce within a short period of time each year. Furthermore, for this study, we are primarily interested in long-term (year to year rather than day to day) population changes. Such annual changes correspond well to the available population census data, which are generally taken on an annual basis. These are arguments in favour of the use of a discrete-time population dynamical model, where the time step is fixed (as opposed to continuous-time models which describe ecological processes as instantaneous rates, for example ordinary or partial differential equation-based models).

While we do not require the individual-level variation of individual-based simulation models, we do need to incorporate some variability among groups of birds in the populations. At the very minimum, 
there is a distinction between juvenile and adult individuals, and often also between breeding and nonbreeding adults. Hence, we need a discrete-time modelling framework able to account for some degree of variation between seabirds, but not necessarily on an individual level. Furthermore, these models must come with a well-developed and non-controversial set of analysis tools. Structured matrix population models (also known as Leslie matrix models) are such a framework (Caswell 2001). These models describe a population as a set of stages, corresponding to age and/or other structuring variables (e.g. breeding/nonbreeding).

Generally, matrix models incorporating age structure are slightly larger and more elaborate than those that do not. However, models using age as a structuring variable are better able to deal with the population dynamics following disturbance events, such as years with exceptionally high or low survival or reproduction. This latter advantage of age-based approaches is especially large when modelling long-lived species such as seabirds. Furthermore, using age as a structuring variable allows for more straightforward interpretation of model parameters. Hence, we choose to use age-based structured matrix population models.

\subsubsection{Model structure}

The assessment of the effect of habitat loss due to OWF deployment on seabirds at the population level will be carried out using stochastic age-structured matrix models. A model will be setup and parameterized for each of the bird species depending on its life cycle and demographic characteristics. Each of the models contains immature and mature age classes. Offspring production occurs in the mature age classes only. In addition, some species have non-reproducing mature classes (so called floaters, see Votier, 2008 and Poot et al., 2011). The proportion of mature individuals that does not breed can be as high as 50\% (Poot et al. 2011). The consideration of non-breeding adults may have a strong effect on the population dynamics (Poot et al. 2011, Lensink \& van Horssen, 2012). Matrix models are discrete-time models; we will use an annual or a seasonal (breeding and winter season) time step depending on the life cycle of the bird and the seasonal pattern in its use of the North Sea.

We plan to model only female birds or breeding pairs. Population models almost never distinguish between males and females. This assumption does not affect model outcomes unless the effect of a disturbance is gender-dependent. Foraging behaviour of seabirds may differ between males and females in some species (Camphuysen et al, 2015). Therefore, we will check for each of the seabirds under study whether a gender-dependent effect is likely to occur.

We aim to take all the birds that use the study area into consideration. This means that we aim to construct a single population model for all birds in the whole North Sea area. However, if the only available information considers specific bird colonies, we may have to revert to a model of one or a few specific colonies.

\subsubsection{Density dependence}

Density dependence may have a strong impact on the population dynamics of seabirds, as well as on the response of these birds to OWF and other disturbances (Furness 2016, Horswill \& Robinson 2015). It has been reported that density-dependence is common in seabirds (Horswill et al, 2017), but this conclusion may suffer from publication bias (Jennions \& Moeller, 2002): studies 'looking for density dependence' with negative results (no density dependence found) are much less likely to get published than those with positive results, leading to over-representation of the latter category in the literatureand hence in meta-analyses like Horswill et al (2017).

Density dependence is commonly included in population models used for assessments (e.g. Poot et al. 2011). This is often deemed necessary because modelled populations without density dependence tend to either grow exponentially or decline to extinction rapidly. Hence, density dependence is often included for technical reasons rather than as an accurate reflection of real-world ecological mechanisms.

Density-dependence comes in two general types: negative and positive. Negative density dependence (or 'compensation') means that a property of individuals (e.g. per capita reproduction) is negatively 
related to population density: it becomes lower as population density increases. This is the type of density-dependence that leads to stable equilibrium in simple logistic population models, because population growth rate is asymptotically reduced as the population approaches carrying capacity. For this type of density-dependence, assuming density independence is precautionary (Horswill et al, 2017), because reduced abundance (resulting from a disturbance) is compensated for by increased growth capacity of the remaining population.

Positive density-dependence (or 'depensation') occurs when per capita growth rates decline with declining population size. This often takes the form of an 'Allee effect', and is caused by for example reduced success in mate finding, or failing group foraging behaviour at low abundance. When positive density dependence occurs, assuming density independence is not precautionary, because positive density-dependence amplifies the magnitude of the disturbance. Depensation in colony-breeding seabirds has been shown almost exclusively in the form of reduced reproductive success in lowdensity colonies (Horswill et al, 2017). While this may be relevant on the level of individual colonies, we expect it to be less relevant on the level of North Sea-wide populations (which are our focus here).

Our approach will be to study the literature and consult experts regarding the occurrence of depensation, and when it does occur, we will assess its relevance on a case by case basis. We then let its relevance guide the degree to which we incorporate it in the population models and scenario studies.

In any case, we will conduct a literature search to determine whether it is likely that density dependence plays a role in the population dynamics of the birds under study. If so, we aim to identify the most likely mechanism for density dependence before including it in the models. While density dependence is likely to play a role in many natural populations, implementing the "wrong" mechanism for density dependence can strongly influence the assessment results, especially in combination with stochasticity. In addition, density dependence complicates model analysis.

We will not implement density dependence in our models unless we find indications of density dependence effects in the bird populations. In case the evidence is inconclusive (and especially in case of potential positive density dependence) we may need to do an analysis with and without density dependence to determine which of the two models predicts a stronger effect of OWFs. However, this would result in substantial extra work and will be discussed with the client if and when it becomes relevant.

\subsubsection{Stochasticity}

Environmental stochasticity is the effect of random variation of the environment, and as a consequence the vital rates, over time. We aim to incorporate the effect of this type of stochasticity in the vital rates of the seabirds in the population model analysis. Our analysis will not consider demographic stochasticity, that stems from random variation between individuals in events such as births and deaths (Caswell 2001).

Matrix population models generally assume that (within each age or stage category) the 'average' individual provides an accurate representation of the population. This is a valid assumption as long as there is no trait inheritance (evolution) and the fitness effect of an equal-sized positive and negative deviation in parameter values is approximately equal (but in the opposite direction). In other words, the increased fitness of an increase in survival from $X$ to $X+\Delta$ approximately equals the fitness decrease of a change from $X$ to $X-\Delta$.

Parameterization of the models will be based on values that we can find in the literature and through our partners. Some of the groundwork has been done for previous assessment studies on most of the seabird species (Poot et al. 2011, Furness 2016, Dierschke et al. 2017, Horswill \& Robinson 2015). To estimate ranges of stochastic fluctuation in the vital rates of the seabirds, we aim to find information in the literature and with the help of partners about variability in breeding success and mortality. For the species for which information is only sparsely available, we will try to estimate stochasticity in vital 
rates from time series data. The possible range of parameter values will allow analysis of environmental stochasticity in the vital rates of the seabirds.

\subsubsection{Analysis}

Based on bird life history details and vital rates, we can calculate the population growth rate of the different seabirds. A sensitivity/elasticity analysis of the population growth rate shows how perturbations in the vital rates (parameter values) of the species may affect the population. This will allow us to assess which part of the birds life cycle will be most sensitive to change. A calculation of the population growth rate with and without the OWFs will show how the population recovery potential is affected by OWFs.

The population models can be used to make projections of specific seabird populations and of the effect of OWFs on the seabird populations that occupy the Southern North Sea. To make an explicit link between model and population data, data on population abundances and population composition (for specific colonies or the whole study area) will be used for comparison with the model output. The previous steps in the analysis will provide estimates of the effect of OWFs on the birds' vital rates. Based on these values, we can do projections of the density of the seabirds with and without the effect of OWFs. In addition, we can calculate the extinction probability of the different populations. Different scenarios, ranging from best to worst case, can be simulated. This will thus allow for an estimate of the population level impact of OWFs following the precautionary approach principle in relation to parameter uncertainty. The reliability of the model outcomes depends on the data quality of vital rates and population sizes that are available.

Our proposed analysis is substantially more elaborate than that presented in Poot et al. (2011):

1. We use a seasonal instead of an annual time step in our models, which allows for the study of wind farms near breeding sites and those that are not (either separately or in cumulation).

2. The existing work modelled a specific colony of guillemots and razorbills in Scotland and the Bass Rock colony for the Northern gannet (Poot et al. 2011). We aim to construct a single model for the population of all birds that inhabit the study area, not individual models for individual colonies.

3. We will investigate indications for density dependence in the bird populations. The density dependent process that is implemented in the population models may differ between bird species.

4. The model for the red-throated diver will be newly developed.

5. We will conduct a sensitivity analysis of the population growth rate in addition to the population projections.

6. We will include environmental stochasticity to estimate its effect on the (un)certainty of our results.

7. We aim to make a rough estimate of the (minimum) carrying capacity of the study area with and without OWFs.

\subsubsection{Species specific considerations}

Below we list a number of species-specific considerations relevant to the population dynamic models of the various species.

\section{Red-throated diver (Gavia stellata)}

Overwintering in the North Sea, breeds in lakes in Northern Europe. Contrary to the other species in this study, red-throated diver is not a colonial breeder. OWFs may affect the overwintering and migration survival. If birds arrive at the breeding grounds in a less favourable physical condition, or arrival is delayed as a consequence of OWFs, there may also be a carry-over effect on breeding success.

There is a lot of uncertainty in the abundances and characteristics of this species because it has not been extensively studied and the breeding grounds lie widely dispersed. To allow for the differences in uncertainty between the parameterization of the breeding and wintering season we will use a model 
with a seasonal time step. This way, uncertainty about the survival probabilities and emigration or immigration in the breeding season can be separated from what happens in the winter season.

Before we develop the population model we need to consider whether sufficiently reliable data for parameterization and validation of the model is available. Partners are hopefully able to help with information on vital rates and estimates of the number of individuals wintering in the Southern North Sea.

\section{Northern gannet (Morus bassanus)}

Breeds in the North Sea area, such as in the Helgoland, Bass Rock and Bempton Cliffs colonies. Part of the individuals of $5+$ years old overwinter throughout the North Sea. All juveniles and part of the adults migrate South and overwinter around Spain and West Africa. OWFs may directly affect the breeding success and winter survival and perhaps have a delayed effect on the survival during migration (of the migratory part).

Since the breeding colonies of the gannet are situated at large distances from the Dutch OWFs, it is likely that breeding is not directly affected by the Dutch OWFs. Yet, we will test this assumption with the habitat modelling step. Because this analysis aims to take the development of OWFs in the whole North Sea into account, the effect of OWFs in UK waters also needs to be considered. UK wind farms may affect the breeding success of Northern gannets if they interfere with the foraging area used by birds from the breeding colonies. The population model for these birds will therefore have a seasonal time step that allows for the incorporation of the effect of UK OWFs in the breeding season and the effect of Dutch OWFs in the wintering season separately.

We can use the matrix model developed by Bureau Waardenburg for the "Bass Rock" gannet colony as a basis. Generally there is a lot of information on the breeding colonies of gannets and we may want to extend the model by adding other colonies. In order to determine the relevant population for the assessment, we need to determine the origin (in terms of breeding colony) of those individuals that encounter OWFs while wintering in the North Sea. Reliable estimates of vital rates for the appropriate breeding colonies, if available at all, requires collaboration with colleagues from the UK and Germany (Daunt, Garthe, Harris, Wanless).

\section{Razorbill (Alca torda) and common guillemot (Uria aalge)}

Razorbills and guillemots breed (mixed colonies) and overwinter in the North Sea. Different areas of the North Sea are used for breeding (NW area, for example around NE Schotland and Ireland) and overwintering (whole North Sea). Dutch OWFs are placed in the overwintering area of these birds and may therefore affect the overwintering survival and perhaps reproduction, if an OWF-related reduced adult condition at the end of winter affects the breeding success.

Because this analysis aims to take the development of OWFs in the whole North Sea into account, the effect of OWFs in UK waters also needs to be considered. UK wind farms may affect the breeding success of razorbills and guillemots if they interfere with the foraging habitat of birds in the breeding colonies. The model for these birds will therefore have a seasonal time step that allows for the incorporation of the effect of UK OWFs in the breeding season and the effect of Dutch OWFs in the wintering season separately.

Bureau Waardenburg has previously developed an age-structured matrix model for a Scottish razorbill and guillemot population that can be used as a basis. The model will be adjusted such that it is suitable for the wintering populations of these species in the Southern North Sea. There will be two different models for these species because there are differences in the life history parameters and the diet. Because their foraging strategies differ, it is likely that the OWFs affect the species differently.

In order to determine the relevant population for the assessment, we need to determine the origin (in terms of breeding colony) of those individuals that encounter OWFs while wintering in the North Sea. However, at present little is known about the origin of the birds (razorbill and guillemot) wintering in the North Sea (Leopold 2017). Reliable estimates of vital rates for the appropriate breeding colonies, if available at all, requires collaboration with colleagues from the UK (Daunt, Harris, Wanless). 


\section{Sandwich tern (Thalasseus sandvicensis)}

Breeds in the North Sea, with large colonies in the Wadden Sea and the Dutch Delta, and winters in West Africa. OWFs may affect the breeding success directly and have a delayed effect on the survival of individuals during the migration and overwintering period by affecting the energetic state of fledglings and parents at the end of the breeding season.

The life cycle for this species can be modelled with an annual time step. Bureau Waardenburg has previously developed an age-structured matrix model for sandwich tern in the Netherlands that can be used as a basis. Depending on the output from the habitat model we may want to use different colonies or do an analysis for specific colonies in the Southern North Sea.

The main Sandwich Tern colonies in the study area are situated in the Netherlands. Detailed information exists for these tern populations.

\subsubsection{Data requirements and availability}

Population dynamical models require parameter values, which determine the speed at which reproduction, mortality, immigration and emigration take place, given the population state (e.g. population size) and the environmental state (e.g. food availability). Each of these parameters is generally the result of an extensive data analysis based on lab and/or field studies. In bird research these field studies generally take the form of ringing studies (or other mark/recapture methods) to estimate mortality and migration, and direct measurement of reproductive success in colonies to estimate reproduction.

For population modelling, the species-, population or colony-specific parameter values are the most relevant information needed. Furthermore, for calibration of the models, population census data, preferably for multiple years and including the various life stages, are essential. The most important sources of this information are listed in the table below, and in the references listed in those papers and reports. Four of the birds under study breed elsewhere (UK, Scandinavia, Russia) and only overwinter in the study area, we hope to find out from which colony the birds that come to overwinter in our part of the North Sea originate. This will allow us to focus on the colonies that are relevant to our study of OWF effects. The disturbance related to UK OWFs is colony specific. In addition, some of the parameterization may be colony specific.

\section{Topic of study}

Assessment of population level effects of Egmond aan Zee wind park on Dutch Seabirds

Literature review of seabird ecology Furness 2016 and population ecology and potential effects of OWFs

Study on red-throated diver

\section{Source}

Poot et al. 2011

\section{Park on Dutch Seabirds}

\author{
ird ecology Furness 2016
}

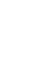




\section{Work plan}

\subsection{Team}

\subsubsection{People}

\subsubsection{Project management}

Overall project leader is Tobias van Kooten. Backup project leader is Floor Soudijn.

\subsubsection{Modelling \& analysis}

Population modelling: Floor Soudijn, Tobias van Kooten, 1 external (preferably Astrid Potiek, BuWa). External consultant population modelling: Prof. H. Caswell (University of Amsterdam).

Habitat modelling: Geert Aarts, Daan Gerla, Chun Chen, Tobias van Kooten.

Avoidance modelling: Daan Gerla, Tobias van Kooten.

Energy budget modelling: Tobias van Kooten, Floor Soudijn.

\subsubsection{Seabird expertise by species}

A large number of experts, both national and international, will be consulted and/or involved in the work.

Red-throated diver (Gavia stellata)

Mardik Leopold

Ruben Fijn

Ramunas Zydelis

Stefan Garthe

Ib Krag Petersen

\section{Northern gannet (Morus bassanus)}

Ruben Fijn

Sara Wanless

Stefan Garthe

\section{Razorbill (Alca torda) and common} guillemot (Uria aalge)

Ruben Fijn

Kees Camphuysen

Mardik Leopold

Mike Harris

Sara Wanless

Francis Daunt
Diet data from found carcasses

MWTL count data

Species ecology

Species ecology

Species ecology

MWTL count data

Species ecology, relevant colony measurements/gps data, Bass Rock colony (largest)

Species ecology, relevant colony measurements/gps data, Helgoland colony (closest by)

MWTL count data

Diet data from found carcasses

Diet data from found carcasses

Species ecology, relevant colony measurements

Species ecology, relevant colony measurements

Species ecology, relevant colony measurements, statistical models 


\section{Sandwich tern (Thalasseus}

\section{sandvicensis)}

Mardik Leopold

Ruben Fijn

Eric Stienen

Vogeltrekstation (Henk van der Jeugd)
Colour ringing, colony dynamics Netherlands

Colour ringing, colony dynamics Netherlands, MWTL count data, GPS-tracking data

Colony dynamics Belgium, coulor ringing

Historical ringing data

\subsection{Work organization}

\subsubsection{Client involvement}

Together with Bureau Waardenburg we will organize a project meeting at WMR in IJmuiden in January/February 2018 with Rijkswaterstaat. The objective of this meeting will be to report on the general progress, motivate and discuss the modelling choices we have made (regarding, for example, density dependence and the inclusion of non-breeding adults) and the implications and dilemmas which these choices lead to.

Furthermore, we foresee a progress meeting with RWS every 2 months, of (at least) Tobias van Kooten and Floor Soudijn with Maarten Platteeuw and Suzanne Lubbe. Whenever developments within the project require RWS involvement (for example, strategic choices need to be made, or decisions with financial implications), the WMR project leadership will contact the appropriate counterparts at RWS. These meetings will be preferably held in IJmuiden to minimize travel time.

\subsubsection{Project team communication}

A good working relationship already exists between WMR and Bureau Waardenburg. Astrid Potiek and Floor Soudijn have similar expertise and will have no difficulty working together on the population models. They will be in regular contact to ensure the compatibility between the population modelling approaches used in this work and the work focusing on the effects of bird collisions.

A version control system for sharing modelling code will be set up to work on shared WMRWaardenburg models (the population dynamical models).

Other parties will be contracted whenever needed.

\subsubsection{Timing}

The work described here will start as soon as the offer is approved. We expect operational versions of the population and avoidance models to be ready by the $1^{\text {st }}$ of February 2018 , and operational versions of the Habitat models by the $1^{\text {st }}$ of March 2018. The code for the energy budget models to convert habitat model output into effects on vital rates will also be ready by the $1^{\text {st }}$ of March 2018 , so that at that date, scenario studies can start. At this time, we will have developed insight into the effects of various kinds of uncertainty, and will be able to advise on which potential field studies could reduce the most relevant uncertainty.

The period after the $1^{\text {st }}$ of March will be used to run scenarios and improve the models further. The final report will be delivered by the 1st of September 2018. 


\subsection{Accountability}

\subsubsection{Wozep data lab}

All data used in analyses will be stored in the Wozep data lab. This will include input data to the models (e.g. satellite-derived primary productivity data) and output data generated by the models (e.g. habitat maps).

\subsubsection{Reproducibility of analyses \& figures}

Within the Wozep data lab a version control system for sharing and storing computer code will be set up. All modelling and analysis code used in the final report will be stored on that system and will hence be available to RWS and other parties. 


\section{Quality Assurance}

Wageningen Marine Research utilises an ISO 9001:2008 certified quality management system (certificate number: 187378-2015-AQ-NLD-RvA). This certificate is valid until 15 September 2018. The organisation has been certified since 27 February 2001. The certification was issued by DNV Certification B.V. 


\section{References}

Arts F.A. \& Berrevoets C.M. 2007. Monitoring van zeevogels en zeezoogdieren op het Nederlands Continentaal plat 1991-2007. Rapport RIKZ/2007.013. Rijksinstituut voor Kust en Zee/RIKZ, Middelburg.

Araujo H., Bastos-Santos J., Correia Rodrigues P., Ferreira M., Pereira A., Henriques A.C. Monteiro S.S., Eira C. \& Vingada J. (2017). The importance of Portuguese Continental Shelf Waters to Balearic Shearwaters revealed by aerial census. Mar Biol (2017) 164:55. DOI 10.1007/s00227-017-3089-x

Berrevoets, C. M., \& Arts, F. (2002). Ruimtelijke analyses van zeevogels: verspreiding van Alk/Zeekoet op het Nederlands Continentaal Plat. Rapport RIKZ, 2002.0.39.

Black, J., Dean, B., Webb, A., Lewis, M., Okill, D. J., \& Reid, J. B. (2015). Identification of important marine areas in the UK for red-throated divers (Gavia stellata) during the breeding season. JNCC Report 541. Peterborough, UK.

Camphuysen, K. C. J., Shamoun-Baranes, J., Bouten, W., \& Garthe, S. (2012). Identifying ecologically important marine areas for seabirds using behavioural information in combination with distribution patterns. Biological Conservation, 156, 22-29.

Camphuysen, K.C.J., Shamoun-Baranes, J., van Loon, E.E. \& Bouten, W. (2015). Sexually distinct foraging strategies in an omnivorous seabird. Mar. Biol. (Berl.) 162(7): 1417-1428.

Caswell, H. (2001). Matrix population models (2nd ed.). Sunderland: Sinauer Associates, Inc.

Cleasby, I. R., Wakefield, E. D., Bearhop, S., Bodey, T. W., Votier, S. C. \& Hamer, K. C. (2015), Three-dimensional tracking of a wide-ranging marine predator: flight heights and vulnerability to offshore wind farms. J Appl Ecol, 52: 1474-1482. doi:10.1111/1365-2664.12529

Cook, A.S.C.P. \& Robinson, R.A. 2016. Testing sensitivity of metrics of seabird population response to offshore wind farm effects. JNCC Report No. 553. JNCC, Peterborough.

De Roos, A. M., T. Schellekens, T. van Kooten, K. van de Wolfshaar, D. C. Claessen en L. Persson (2007). Food-dependent growth leads to overcompensation in stage-specific biomass when mortality increases: the influence of maturation versus reproduction regulation. American Naturalist 170(3): E59-E76.

Delavenne, J., Toison, V., Blanck, A., \& Ridoux, V. (2017). Habitat modelling predictions highlight seasonal relevance of Marine Protected Areas for marine megafauna. Deep-Sea Research Part II: Topical Studies in Oceanography, 141, 262-274.

Dierschke, V., Furness, R.W. \& Garthe, S. 2016. Seabirds and offshore wind farms in European waters: Avoidance and attraction. Biological conservation 202, 1: 59-68.

doi:10.1016/j.biocon.2016.08.016

Dierschke, V., Furness, R., Gray, C., Petersen, I., Schmutz, J., Zydelis, R., \& Daunt, F. (2017). Possible Behavioural, Energetic and Demographic Effects of Displacement of Red-throated Divers. JNCC Report (Vol. 605).

Fijn R.C., Arts F.A., de Jong J.W., Collier M.P., Hoekstein M., Jonkvorst R.-J., Lilipaly S., Wolf P.A., Gyimesi A., Poot M.J.M. \& Engels B.W.R. (2015) Verspreiding en abundantie van zeevogels en 
zeezoogdieren op het Nederlands Continentaal Plat in 2014- RWS-Centrale Informatievoorziening BM15.20.

Fijn, R.C., J. de Jong, W. Courtens, H. Verstraete, E.W.M. Stienen, M.J.M. Poot (2017) GPS-tracking and colony observations reveal variation in offshore habitat use and foraging ecology of breeding Sandwich Terns. J. Sea Res. 127, 203-211.

Furness, B. (2016). Qualifying impact assessments for selected seabird populations : A review of recent literature and understanding. Report commissioned by Vattenfall, Statkraft and SPR.

Heessen, H.J.L., Daan, N. \& Elllis, J.R. (2015) Fish atlas of the Celtic Sea, North Sea and Baltic sea. KNNV Publishers/Wageningen Academic Publishers, The Netherlands.

Horswill, C., \& Robinson, R. A. (2015). Review of Seabird Demographic Rates and Density Dependence. JNCC Report 552. Peterborough, UK.

Horswill, C., O'Brien, S. H., \& Robinson, R. A. (2016). Density dependence and marine bird populations: Are wind farm assessments precautionary? Journal of Applied Ecology, 1406-1414.

Jennions, M.D. \& Møller, A.P. (2002). Publication bias in ecology and evolution: an empirical assessment using the "trim and fill" method. Biol. Rev. Camb. Philos. Soc. 77, 211-222.

Johnston, A., Thaxter, C. B., Austin, G. E., Cook, A. S. C. P., Humphreys, E. M., Still, D. A., Burton, N. H. K. (2015). Modelling the abundance and distribution of marine birds accounting for uncertain species identification. Journal of Applied Ecology, 52(1), 150-160. Lambert, C., Virgili, A., Pettex, E.,

Kooijman, S. A. L. M. (2009). Dynamic Energy Budgets Theory for Metabolic Organisation. Cambridge, Cambridge University Press.

Garthe, S., Markones, N. \& Corman, A.M. (2017) Possible impacts of offshore wind farms on seabirds: a pilot study in Northern Gannets in the southern North Sea. J Ornithol 158: 345.

Gyimesi, A., \& Lensink, R. (2012). Non-breeding adults or "floaters" in bird populations. Report 11200. Bureau Waardenburg.

Leopold M.F., Booman M., Collier M.P., Davaasuren N., Fijn R.C., Gyimesi A., de Jong J., Jongbloed R.H., Jonge Poerink B., Kleyheeg-Hartman J., Krijgsveld K.L., Lagerveld S., Lensink R., Poot M.J.M. van der Wal J.T. \& Scholl M. 2014. A first approach to deal with cumulative effects on birds and bats of offshore wind farms and other human activities in the Southern North Sea. IMARES Report C166/14.

Leopold, M. F. (2017). Seabirds? What seabirds? An exploratory study into the origin of seabirds visiting the SE North Sea and their survival bottlenecks. Wageningen Marine Research report C046/17. Den Helder.

Mitchell P.I., Newton S.F., Ratcliffe N. \& Dunn T.E. 2004. Seabird populations of Britain and Ireland. Results of the Seabird 2000 census (1998-2002). T \& AD Poyser, London, 511p.

Nur, N., Jahncke, J., Herzog, M. P., Howar, J., Hyrenbach, K. D., Zamon, J. E., Stralberg, D. (2011). Where the wild things are: Predicting hotspots of seabird aggregations in the California Current System. Ecological Applications, 21(6), 2241-2257. http://doi.org/10.1890/10-1460.1Pingree R.D. \& Griffiths D.K. 1978. Tidal fronts on the shelf seas around the British Isles. J. Geoph. Res. 83 C9: 46154622.

Poot, M., Horssen, P. W. Van, Fijn, R. C., Collier, M. P., \& Viada, C. (2010). Do potential and proposed Marine Protected Areas in the Dutch part of the North Sea qualify as Marine Important Bird Areas (MIBAs )? Application of BirdLife selection criteria. Bureau Waardenburg bv. Culemborg, The Netherlands. 
Poot, M., Horssen, P. van W. Van, Collier, M. P., Lensink, R., \& Dirksen, S. (2011). Effect studies offshore wind Egmond aan Zee: cumulative effects on seabirds. Bureau Waardenburg bv, commissioned by Noordzeewind, The Netherlands.

Skov, H., Heinänen, S., Thaxter, C. B., Williams, A. E., Lohier, S., \& Banks, A. N. (2016). Real-time species distribution models for conservation and management of natural resources in marine environments. Marine Ecology Progress Series, 542, 221-234. http://doi.org/10.3354/meps11572

Thaxter, C. B., Cook, A. S. C. P., Johnston, A., \& Burton, N. H. K. (2011). Review and Application of Statistical Techniques to Model the At-sea Distributions of Breeding Sandwich Terns Authors. BTO Research Report No. 582. The Nunnery, Thetford, Norfolk, UK.

Thaxter, C. B., Lascelles, B., Sugar, K., Cook, A. S. C. P., Roos, S., Bolton, M., Burton, N. H. K. (2012). Seabird foraging ranges as a preliminary tool for identifying candidate Marine Protected Areas. Biological Conservation, 156, 53-61.

Votier, S., Birkhead, T., Oror, D., Trinder, M., Grantham, M., Clark, J., Hatchwell, B. (2008).

Recruitment and survival of immature seabirds in relation to oil spills and climate variability. Journal of Animal Ecology, 77, 974-983. http://doi.org/10.1111/j.1365-2656.2007.0

Wakefield, E. D., Bodey, T.W., Bearhop, S., Blackburn, J., Colhoun, K., Davies, R., Dwyer, R. G., Green, J. A., Grémillet, D., Jackson, A. L. et al. (2013). Space partitioning without territoriality in gannets. Science 341, 68-70.

Wakefield, E. D., Owen, E., Baer, J., Carroll, M. J., Daunt, F., Dodd, S. G., Green, J. A., Guilford, T., Mavor, R. A., Miller, P. I., Newell, M. A., Newton, S. F., Robertson, G. S., Shoji, A., Soanes, L. M., Votier, S. C., Wanless, S. and Bolton, M. (2017), Breeding density, fine-scale tracking, and large-scale modeling reveal the regional distribution of four seabird species. Ecol Appl, 27: 2074-2091.

Wetlands International 2010. (Compiled by Simon Delany, Szabolcs Nagy and Nick Davidson). State of the World's Waterbirds, 2010. Wetlands International, Wageningen, The Netherlands 


\section{Justification}

Report C069/18

Project Number: 4315100070

The scientific quality of this report has been peer reviewed by a colleague scientist and a member of the Wageningen Marine Research management team.

Approved: $\quad$ Dr. Ingrid Tulp

Senior scientist

Signature:

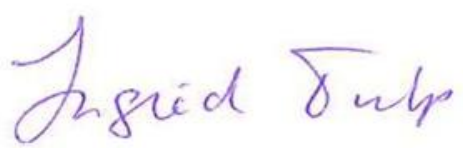

Date:

25 september 2018

Approved:

Drs. J. Asjes

Manager Integration

Signature:

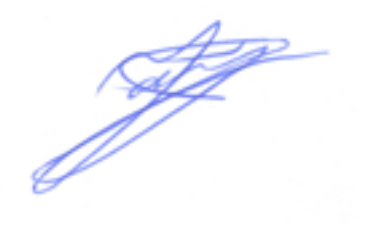

Date:

25 september 2018 
Wageningen Marine Research

$\mathrm{T}+31(0) 317480900$

E imares@wur.nl

www.wur.nl/marine-research

Visitorsadress

- Haringkade 1, 1976 CP IJmuiden

- Korringaweg 7, 4401 NT Yerseke

- Ambachtsweg 8A, 1785 AJ Den Helder

- Bevesierweg 4, Gebouw MML Schiereiland Fort Harssens, 1781 CA Den Helder

- Landsdiep 4, 1797 SZ 't Horntje, Texel
Wageningen Marine Research (Institute for Marine Resources and Ecosystem Studies) is the Netherlands research institute established to provide the scientific support that is essential for developing policies and innovation in respect of the marine environment, fishery activities, aquaculture and the maritime sector.

The Wageningen Marine Research vision

'To explore the potential of marine nature to improve the quality of life'

\section{The Wageningen Marine Research mission}

- To conduct research with the aim of acquiring knowledge and offering advice on the sustainable management and use of marine and coastal areas.

- Wageningen Marine Research is an independent, leading scientific research institute

Wageningen Marine Research is part of the international knowledge organisation Wageningen University \& Research. Within Wageningen UR, nine specialised research institutes of the DLO Foundation have joined forces with Wageningen University to help answer the most important questions in the domain of healthy food and living environment. 